\title{
Bristowe, Grier, Ponce, and Williams to Chair 1999 MRS Fall Meeting
}

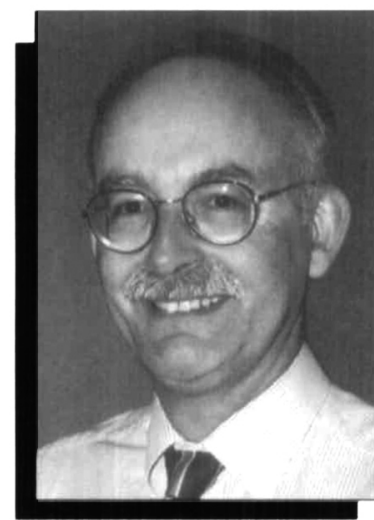

Paul D. Bristowe

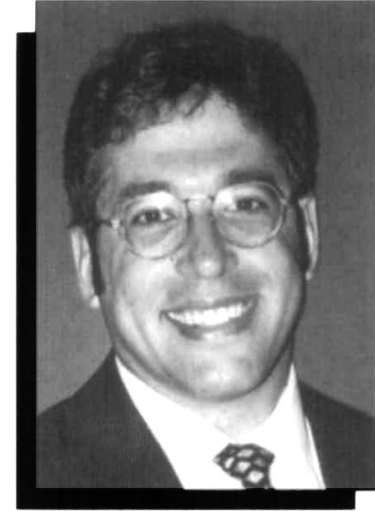

David G. Grier

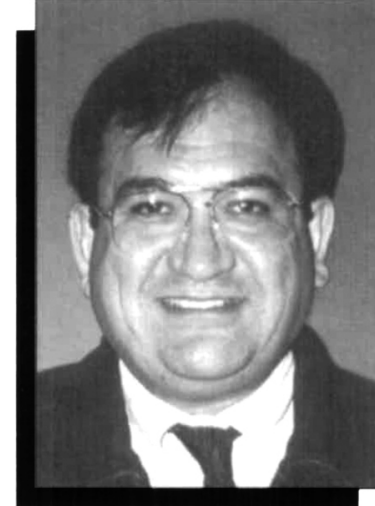

Fernando A. Ponce

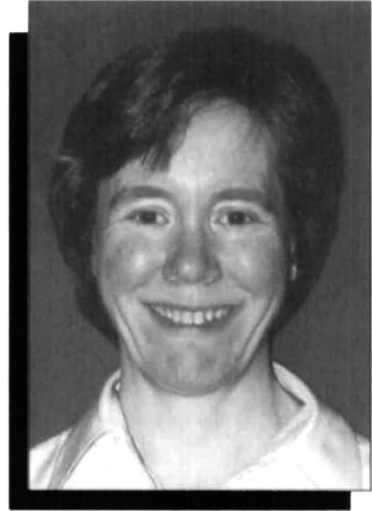

Ellen D. Williams
The Fall 1999 Materials Research Society Meeting in Boston, November 29 to December 3, will be chaired by Paul D. Bristowe (Cambridge University), David G. Grier (University of Chicago), Fernando A. Ponce (Xerox-PARC) and Ellen D. Williams (University of Maryland). Fortythree symposia are planned, many of which will now take place in the Hynes Convention Center adjacent to the Sheraton Boston Hotel. Following recent practice, the technical program will reflect a balance between new and traditional areas of research. Several focus areas have been identified including soft materials, thin film materials, device materials, and materials modeling. Topics in well-established areas will continue to be represented including some with on-going symposia series such as nitride semiconductors, ferroelectrics, nanophase materials, and nuclear waste management.

In the area of soft materials a number of new symposia will be featured. One of them will address the topic of biomineralization and will cover various aspects of mineral formation on natural and synthetic biomaterials. Another will be directed toward the materials science of food and focus on process-structure-property relationships.

The contribution of theory and modeling to materials research will once again be recognized in this Meeting. Five symposia dealing with this subject will be presented, two of which will focus on predicting materials properties from first principles while the others will emphasize approaches based on different length scales and the coupling of models with experimental observation.

The growing importance of thin film technology is reflected in the number of planned symposia in this area. The synthesis, processing, characterization and integration of thin films in various classes of materials including ferroelectrics, dielec- trics, semiconductors, polymers, and amorphous materials will be included.

Paul D. Bristowe has been a lecturer in the Department of Materials Science and Metallurgy at the University of Cambridge since 1994. Prior to his appointment at Cambridge he was a Principal Research Associate at the Massachusetts Institute of Technology. He received his $\mathrm{PhD}$ degree in physics from the University of Surrey in 1975. From 1977 to 1979 he was a Fulbright-Hays Research Scholar at Cornell University. Bristowe's research interests lie in the microscopic modeling of defects in materials, particularly interfaces, using both classical and quantum mechanical methodologies. Current efforts focus on the properties of III-V and II-VI compounds. He is Deputy Editor of Philosophical Magazine $A$ and has been an organizer of five MRS symposia. He is a Fellow of the Institute of Physics and of the Institute of Materials.

David G. Grier is an associate professor of physics in the James Franck Institute at the University of Chicago. He received his $A B$ degree in physics from Harvard College and his PhD degree in physics from the University of Michigan. At the University of Chicago, Grier has focused his efforts on probing the microscopic mechanisms for structural phase transitions with a particular emphasis on measuring the local-scale interactions and dynamics responsible for materials' collective behavior. Grier has served as a guest editor for the October 1998 issue of $M R S$ Bulletin on the theme, "From Dynamics to Devices: Directed Self-Assembly of Colloidal Materials."

Fernando A. Ponce had been at the Xerox Palo Alto Research Center since 1984 and has just joined the faculty at Arizona State University. Previously, he worked at Hewlett-Packard Laboratories in Palo Alto, California for four years. He has contributed to the fields of growth and characterization of photovoltaic materials, the development and characterization of materials for optoelectronic applications, and high-resolution transmission electron microscopy. His current interests are in the understanding of atomic arrangement at defects and interfaces in semiconductors, and in the materials properties and correlation to growth and to device performance of the nitride semiconductors. Ponce has organized several MRS symposia, including the First International Symposium of GaN and Related Materials at the 1995 Fall Meeting, the Symposium on III-V Nitrides at the 1996 Fall Meeting, and the Symposium on Nitride Semiconductors at the 1997 Fall Meeting.

Ellen D. Williams is a professor in the Department of Physics and the Institute for Physical Science and Technology at the University of Maryland and director of the University's Materials Research Science and Engineering Center. Williams's current research interests are in the experimental study and modeling of surface morphology on atomic- to micron-length scales using real-time imaging techniques such as scanning tunneling microscopy and low-energy electron microscopy. Her other research interests include development and application of statistical analysis techniques for evaluating real-space images in terms of energetics and kinetics; studies of the limits on the stability of small structures posed by thermal fluctuations; and studies of interface evolution under growth, etching, electromigration, and stress. Williams has served as principal investigator for the NSF Materials Research Group (1991-1996), and she has served on the Executive Committee of the Surface Science Division of the American Vacuum Society (1989-1990), the Editorial Advisory Board of Surface Science (19951998), and the Editorial Board for Review of Scientific Instruments (1991-1993). 